\title{
Glycemic Control of Non-Hodgkin Lymphoma (NHL) Non-Diabetes Mellitus (DM) Patient in the First CHOP Chemotherapy
}

\author{
Jualita Heidy Saputri ${ }^{1}$, Hermina Novida ${ }^{2}$, Ami Ashariati ${ }^{3}$ \\ ${ }^{1}$ Resident, Department of Internal Medicine, Dr. Soetomo Teaching Hospital, Airlangga University Faculty of \\ Medicine, Indonesia, ${ }^{2}$ Lecturer, Division of Endocrinology, Diabetes, and Metabolism, Department of Internal \\ Medicine, Dr. Soetomo Teaching Hospital, Airlangga University Faculty of Medicine, Indonesia, ${ }^{3}$ Professor, \\ Division of Medical Oncology, and Hematology, Department of Internal Medicine, Dr. Soetomo Teaching Hospital, \\ Airlangga University Faculty of Medicine, Indonesia
}

\begin{abstract}
Non-Hodgkin's lymphoma (NHL) chemotherapy is cyclophosphamide, doxorubicin, vincristine, and prednisone (CHOP) have hyperglycemia side effects that affect the success of chemotherapy. Improved glycemic control decreases morbidity and mortality. Determine the glycemic control changes in non-DM NHL patients before and the sixth day after the first CHOP chemotherapy.

Method: Prospective longitudinal observational analytic study in the Internal Medicine Inpatient Unit Dr. Soetomo Teaching Hospital Surabaya, involved all the first CHOP chemotherapy NHL patients during November 2019-February 2020. A total of 21 patients met chemotherapy requirements and were not DM. The glycemic control check uses the hexokinase method and a glucometer (Easy Touch ${ }^{\circledR}$ ). Data analysis using the Wilcoxon test was considered significant if $\mathrm{p}<0.05$.

Results: Total research subjects were 21 people, female domination (66.7\%), mean age $49.24 \pm 13.96$ years, clinical stage 3 dominance (52.38\%), mean HbA1C $5.75 \pm 0.49 \%$, average FBG $90.86 \pm 13.13 \mathrm{mg} / \mathrm{dL}$, the mean PPBG $114.33 \pm 20.16 \mathrm{mg} / \mathrm{dL}$. Daily blood glucose levels during chemotherapy were highest on the first day's pre-dinner. There were significant differences in FBG and PPBG before chemotherapy and the sixth day after chemotherapy (p-values 0.032 and 0.002 ). The incidence of new-onset DM on the sixth day after the first CHOP chemotherapy was 2 subjects $(9.53 \%)$.
\end{abstract}

Conclusion: There was an increase in FBG and PPBG of NHL non-DM patients before and the sixth day after the first CHOP chemotherapy.

Keywords: $N H L, D M, C H O P$.

\section{Introduction}

Malignant lymphoma is the primary malignancy of lymph nodes and lymphoid tissue. Based on the presence

\section{Corresponding Author:}

\section{Dr. Hermina Novida}

Lecturer, Division of Endocrinology, Diabetes, and Metabolism, Department of Internal Medicine, Dr. Soetomo Teaching Hospital, Airlangga University Faculty of Medicine, Indonesia e-mail: herminanovida@ymail.com of Reed-Sternberg cells, they are divided into Hodgkin's lymphoma (HL) and non-Hodgkin's lymphoma (NHL) ${ }^{1}$. One of the ten most severe malignancies in the world is malignant lymphoma with a prevalence of $3.37 \%$. Its incidence worldwide has increased by $3-4 \%$ in the last 4 decades with the incidence of NHL $6 \%$ in men and $4.1 \%$ in women ${ }^{1-2}$. In America there are 74,200 new cases (4.2\%), 19,970 (3.3\%) of whom died from NHL, and life expectancy for the next 5 years by $72 \%{ }^{3}$. Ministry of Health of the Republic of Indonesia in 2013, the incidence of lymphoma in Indonesia was $0.06 \%$ with an estimated 14,905 patients and 2,296 of them were 
from East Java Province ${ }^{1}$. This data shows that NHL is a common malignancy with sufficient mortality and high life expectancy. Therapeutic modalities in NHL patients are chemotherapy and radiation. The choice of first-line chemotherapy is a combination of cyclophosphamide, doxorubicin, vincristine, and prednisone $(\mathrm{CHOP})^{4-5}$.

One of side effect CHOP chemotherapy is hyperglycemia ${ }^{5-6}$. Hyperglycemia is a condition of an increase in blood glucose more than normal that can progressively become a metabolic disease (diabetes mellitus/DM). A 2013 Japanese study stated that 32.5\% of patients with NHL without a history of DM who received CHOP chemotherapy will become $\mathrm{DM}^{7}$. In the same year, a study in Mexico revealed $40.6 \%$ of the DM's incidencein NHL patients and acute lymphoblastic leukemia due to the use of high-dose glucocorticoids associated with chemotherapy ${ }^{8}$. In 2018, research in the USA stated that $47 \%$ of NHL patients experienced episodes of hyperglycemia in the first week after RCHOP or REPOCH chemotherapy ${ }^{9}$.

Hyperglycemia is influential on the quality of human resources and has an impact on a significant increase in health $\operatorname{costs}^{10-11}$. Chemotherapy-related hyperglycemia can cause acute complications in the form of infections, sepsis, ketoacidosis (3.6\%), hyperosmolar non-ketotic (7.2\%), acute hyperglycemia syndrome, and dehydration ${ }^{11-15}$. In addition, hyperglycemia can affect the result of chemotherapy, the rate of cancer recurrence, and resistance to chemotherapy agents. Blood glucose control during chemotherapy is important in terms of success chemotherapy, life expectancy of cancer patients, reducing morbidity, mortality, and affects decreasing health insurance financing ${ }^{13-14,17}$. Components assessed were glycemic control in the form of fasting blood glucose (FBG) and 2 hours postprandial blood glucose (PPBG) when the patient was before chemotherapy and evaluated after getting the first CHOP chemotherapy.

\section{Material and Method}

This was aprospective observational study with pre and posttest design. The population of this study was NHL patients who have been diagnosed and come for chemotherapy in the internal medicine ward of Dr. Soetomo general hospital, Surabaya. Sample size calculated from the following formula: $n=\left[\frac{(z \alpha+z \beta) s}{x 1-x 2}\right]^{2}$, which standard deviation from the previous study was 0.64 and a confidence interval of $95 \%$ therefore, a minimum of 17 subjects needed. Subjects were recruited totally. Subjects with DM type 2 in the first screening, under certain medication (corticosteroid, antioxidant), had an adverse event or serious adverse event during the procedure, or refuse to join this study were excluded from this study. All cases included in this study were subjected to complete informed consent, clinical history, clinical evaluation, sampling blood vein, and capillary blood. Three $\mathrm{mL}$ blood vein samples were collected from the subjects in the morning ( $8-10$ a.m.), under fasting conditions for at least 8 hours for FBG, lipid profile, and $\mathrm{HbA1C}$. Then subjects had breakfast, fasting again in 2 hours, and $3 \mathrm{~mL}$ blood vein samples were collected again for PPBG. This procedure in a day before chemotherapy (the first-day) and the sixth-day chemotherapy. During the procedure of chemotherapy, the subject had capillary blood sampling 15-30 minutes before breakfast, lunch, dinner, and bedtime.

Glycemic control was an examination of glucose levels consisting of fasting blood glucose (FBG) and 2-hour postprandial blood glucose $(\mathrm{PPBG})^{10}$. Premeal (before breakfast, lunch, and dinner) and bedtime glucose were also components of glycemic control will be examined in this study. If in the duration of the study an increase in blood glucose is found, it will be consulted to the endocrine, metabolic, and diabetic divisions to determine whether DM or not and to determine whether interventions that are following the IEA 2019 standards are to be followed throughout the study period.

Fasting blood glucose (FBG) is a glucose level that is checked in fasting for 8 hours. Normal result if less than $100 \mathrm{mg} / \mathrm{dL}$. Postprandial blood glucose (PPBG) is a glucose level that is checked in the condition after eating in regular portions (equivalent to 75 grams of glucose) and followed by fasting for 2 hours. Normal result if it is less than $140 \mathrm{mg} / \mathrm{dL}$. HbA1C is the level of glycated hemoglobin in the blood that is examined in a state of fasting for 8 hours. Normal result if it is less than 5.7\%. Prediabetes if obtained FBG 100-125 mg/dL, PPBG $140-199 \mathrm{mg} / \mathrm{dL}$, and/or HbA1C 5.7-6.4\%. DM if FBG> $126 \mathrm{mg} / \mathrm{dL}, \mathrm{PPBG}>=200 \mathrm{mg} / \mathrm{dL}$, and/or HbA1C> $=6.5 \%{ }^{10}$. Venous blood sampling was around $3 \mathrm{~mL}$ and processed using a Dimension Exl device with the hexokinase method in the clinical pathology laboratory Dr. Soetomo Surabaya.

Pre-meal glucose levels are glucose levels that are checked 15-30 minutes before a large meal in the morning, afternoon, and evening. Glucose bedtime is a glucose level that is checked before going to bed at 
night. Results are considered normal when 80-99 mg/ $\mathrm{dL}$ in non-DM individuals ${ }^{18}$. Data were obtained from supporting examinations in the form of capillary blood collection which were processed using an Easy Touch $^{\circledR}$ glucometer.

CHOP chemotherapy (cyclophosphamide/ doxorubicin/vincristine/prednisone) is the first-line regimen for NHL patients recommended by the Ministry of Health and/or NCCN for NHL patients for the first time. Doses given cyclophosphamide $750 \mathrm{mg} / \mathrm{m}^{2}$ body surface area (BSA)/day/intravenously, doxorubicin $50 \mathrm{mg} / \mathrm{m}^{2} \quad \mathrm{BSA} /$ day/intravenously, vincristine 1.4 $\mathrm{mg} / \mathrm{m}^{2} \mathrm{BSA} /$ day/intravenously for the first day, and prednisone $60 \mathrm{mg} / \mathrm{m}^{2} \mathrm{BSA} /$ day/orally for 5 days per cycle $^{4-5}$. Premedication was given before chemotherapy includes dexamethasone $10 \mathrm{mg}$ intravenously, diphenhydramine $10 \mathrm{mg}$ intravenously, and ondansetron $8 \mathrm{mg}$ intravenously. Intravenous chemotherapy agents are given in the afternoon. Prednisone is given on the first day at 5.00 p.m. On days 2, 3, 4, and 5 prednisone is given at $7.00 \mathrm{a} . \mathrm{m}$.

Chemotherapy requirements include performance status with a karnofsky score of more than $60 \%$, hemoglobin more than $10 \mathrm{~g} / \mathrm{dL}$, leukocytes more than $4,000 / \mathrm{mL}$, platelets more than $100,000 / \mathrm{mL}$, serum transaminases are not more than 1.5 times the normal price, albumin is more than or equal to $2.5 \mathrm{~g} / \mathrm{dL}$, creatinine clearance of more than $70 \mathrm{~mL} / \mathrm{min}^{19}$. Besides, research subjects were also screened for HIV infection, hepatitis B and Cvirusesinfection, and tuberculosis infections.
Statistical analysis performed using SPSS for Windows version 22.0. Univariate analysis performed to describe the characteristics of the subjects. Bivariate analysis performed using T-tests if data is normally distributed otherwise, the Wilcoxon test will be used. The normality test performed using the Shapiro-Wilk test.

\section{Results}

The total number of NHL patients who received the first CHOP chemotherapy during the period November 2019 - February 2020 and met the inclusion criteria was 21 patients. Subjects were dominated by female sex (66.7\%), while male sex was $33.3 \%$. The average age of the study subjects was $49.24 \pm 13.96$ years. In men, the average waist circumference is $86 \pm 5.89 \mathrm{~cm}$. In women, the average waist circumference was $94.14 \pm 16.31$ $\mathrm{cm}$. The average body mass index (BMI) was $23.45 \pm$ $4.72 \mathrm{~kg} / \mathrm{m} 2$ with the domination of normal BMI was 7 subjects (33.3\%). The dominance of NHL clinical stage 3 based on Ann Arbor was 11 people (52.38\%). Median total cholesterol is $163 \mathrm{mg} / \mathrm{dL}$, median triglyceride is $136 \mathrm{mg} / \mathrm{dL}$, median HDL is $34 \mathrm{mg} / \mathrm{dL}$, and mean LDL is $108.52 \pm 20.92 \mathrm{mg} / \mathrm{dL}$. Characteristics of $\mathrm{HbAlC}$ with an average of $5.75 \pm 0.49 \%$. The average research subject's FBG and PPBG was $90.86 \pm 13.13 \mathrm{mg} / \mathrm{dL}$ and $114.33 \pm 20.16 \mathrm{mg} / \mathrm{dL}$. Risk factors for increased glycemic control include overweight - obesity by 8 subjects, dyslipidemia by 15 subjects, hypertension by 5 subjects, and smokers by 3 subjects.

Table 1. General characteristics of the subjects

\begin{tabular}{|l|l|c|c|c|c|}
\hline \multicolumn{2}{|c|}{ Characteristic } & n (\%) & Average \pm SD* & Median** & Range \\
\hline \multirow{3}{*}{ Gender* } & Male & $14(66,7)$ & & & \\
\hline & Female & $7(33,3)$ & & & \\
\hline \multirow{4}{*}{ Age** } & $18-60$ years & $18(85,7)$ & \multirow{2}{*}{$49,24 \pm 13,96$} & & $27-77$ \\
\hline & More than 60 years & $3(14,3)$ & & & $65-122$ \\
\hline \multirow{5}{*}{ Waist Circumferences* } & Female & & $94,14 \pm 16,31$ & & \\
\cline { 2 - 6 } & Less than $80 \mathrm{~cm}$ & $2(14,3)$ & & & \\
\cline { 2 - 6 } & More than $80 \mathrm{~cm}$ & $12(85,7)$ & & & \\
\cline { 2 - 6 } & Male & & $86-96$ \\
\hline & Less than $90 \mathrm{~cm}$ & $5(71,4)$ & & & \\
\hline & More than $90 \mathrm{~cm}$ & $2(28,6)$ & & & \\
\hline
\end{tabular}




\begin{tabular}{|c|c|c|c|c|c|}
\hline \multicolumn{2}{|c|}{ Characteristic } & \multirow{2}{*}{$\frac{\mathbf{n}(\mathbf{\%})}{5(23,8)}$} & Average \pm SD* & Median** & Range \\
\hline \multirow{4}{*}{ Body Mass Index (BMI)* } & Less than $18,5 \mathrm{Kg} / \mathrm{m}^{2}$ & & \multirow{4}{*}{$23,45 \pm 4,72$} & & \multirow{4}{*}{$16-35,4$} \\
\hline & $18,5-25,0 \mathrm{Kg} / \mathrm{m}^{2}$ & $8(38,1)$ & & & \\
\hline & $25,0-30,0 \mathrm{Kg} / \mathrm{m}^{2}$ & $7(33,3)$ & & & \\
\hline & More than $30 \mathrm{Kg} / \mathrm{m}^{2}$ & $1(4,8)$ & & & \\
\hline \multirow{4}{*}{ Clinical Staging of NHL* } & Stage I & $2(9,52)$ & & & \\
\hline & Stage II & $7(33,33)$ & & & \\
\hline & Stage III & $11(52,38)$ & & & \\
\hline & Stage IV & $1(4,76)$ & & & \\
\hline \multirow{4}{*}{ Lipid Profile } & Choleteroltotal* & & & 163 & $121-304$ \\
\hline & Trigliserida* & & & 136 & $45-478$ \\
\hline & HDL* & & & 34 & $14-156$ \\
\hline & $\mathrm{LDL}^{* *}$ & & $108,52 \pm 20,92$ & & $74-140$ \\
\hline \multicolumn{2}{|l|}{$\mathrm{HbA1C} * *$} & & $5,75 \pm 0,49$ & & $4,6-6,4$ \\
\hline \multicolumn{2}{|l|}{$\mathrm{FBG}^{* *}$} & & $90,86 \pm 13,13$ & & $73-122$ \\
\hline \multicolumn{2}{|l|}{ PPBG** } & & $114,33 \pm 20,16$ & & $85-155$ \\
\hline
\end{tabular}

The effect of chemotherapy on FBG and PPBG levels in this study was statistically significant $(\mathrm{p}=0.032$ and $\mathrm{p}=0.002$ ) with a significance level of $5 \%$. In our study, the average increase in FBG was $177.5 \pm 28.99 \mathrm{mg} / \mathrm{dL}$ and PPBG $239.5 \pm 58.69 \mathrm{mg} / \mathrm{dL}$.

Table 2. Characterics of the subjects associated with glycemic control

\begin{tabular}{|l|l|c|c|}
\hline \multicolumn{2}{|l|}{ Blood Glucose } & Median (Minimum- Maksimum) & P-Value \\
\hline \multirow{2}{*}{ FBG } & Day 1 & $87(73-122)$ & \multirow{2}{*}{0,032} \\
\cline { 2 - 3 } & Day 6 & $96(76-198)$ & \\
\hline \multirow{2}{*}{ PPBG } & Day 1 & $113(85-155)$ & 0,002 \\
\cline { 2 - 3 } & Day 6 & $126(98-281)$ & \\
\hline
\end{tabular}

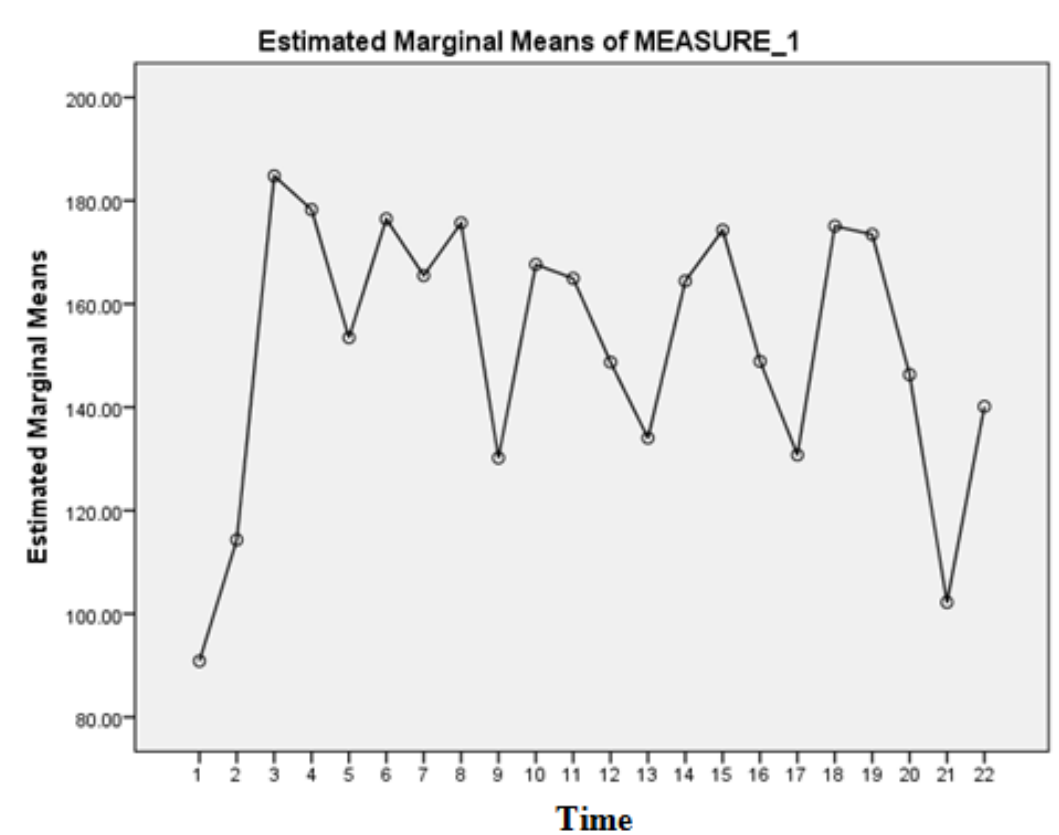

Figure 1. Trend analysis of Anova Repeated Measurement glycemic control's subjects 
Figure 1 shows a trend graph analysis of Anova Repeated Measurement glycemic control of subjects. The graph above shows the peak increase in blood glucose levels during the first day's pre-dinner. Daily glycemic control is dominated by an increase in prelunch blood glucose levels which is then followed by a decrease at pre-dinner, bedtime, and pre-breakfast the next day.
Figure 2 shows the number of subjects who had diabetes, pre-diabetes, and normally based on FBG, PPBG, and/or HbA1C before chemotherapy and the sixth day of chemotherapy. Before chemotherapy, there were 5 subjects with pre-diabetes and 16 non-diabetic. On the 6th day of chemotherapy, there were 2 new DM incidents $(9.53 \%)$ and 7 with prediabetes $(33.33 \%)$.

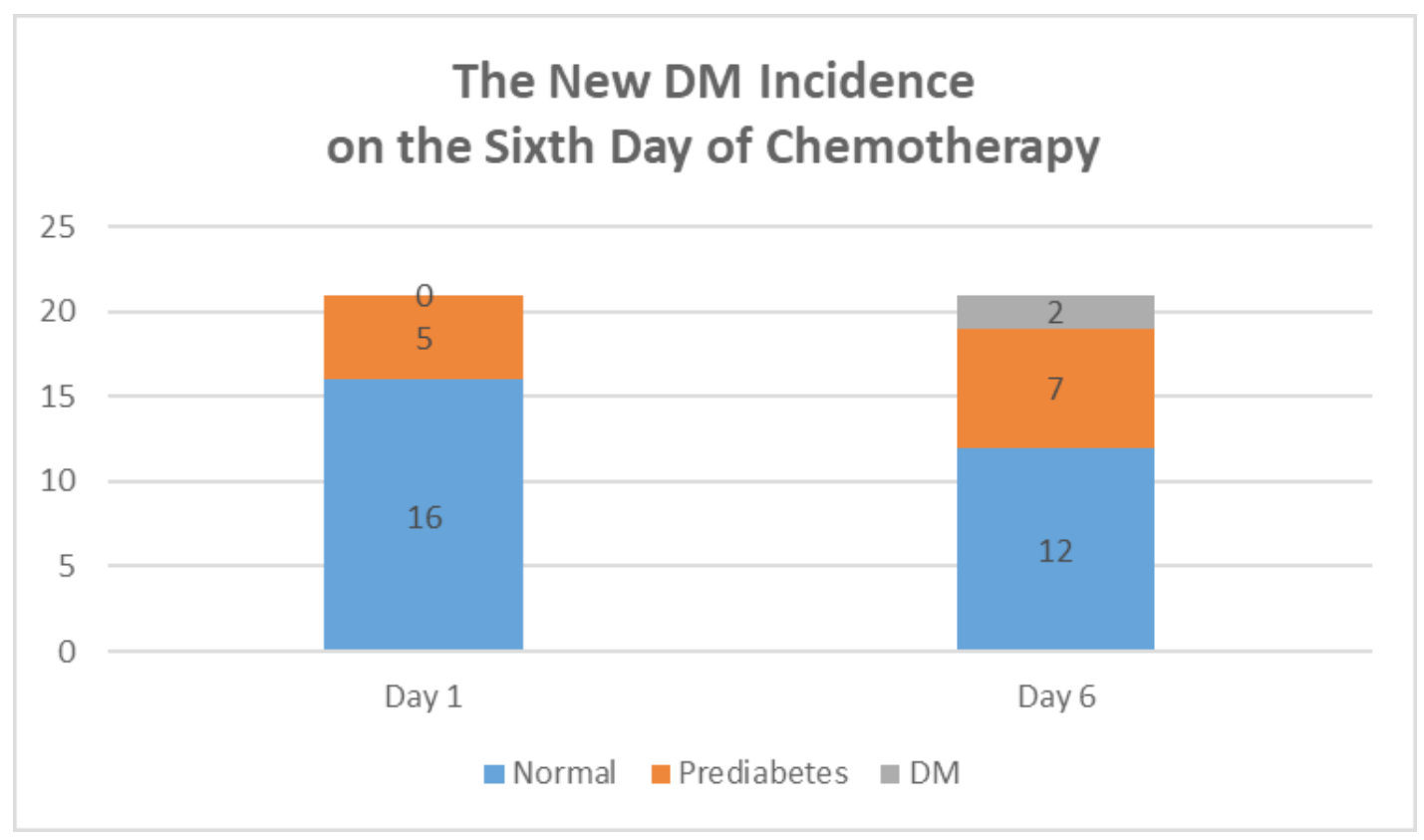

Figure 2. Incidence of DM in the sixth day of chemotherapy

\section{Discussion}

Glycemic control on the first day until the fifth day of chemotherapy was varied on the subjects. The examination is carried out to determine the peak increase in blood glucose levels so that early detection and intervention can be done. The peak during pre-dinner the first day of chemotherapy-related to the administration of CHOP agents and premedication in the form of dexamethasone. The dominance of increased daily blood glucose levels at pre-lunch and pre-dinner and back down at bedtime and pre-breakfast the next day. This shows the predominance of an increase in blood glucose levels after the administration of chemotherapy agents at 7.00 am on the second to the fifth chemotherapy day. The results of this study are in line with the theory presented in the study of Lee et al (2013) that an increase in glucose occurs after 6-8 hours after the chemotherapy agent is given and dominate more on increasing PPBG. Prednisone has a medium service life, peak concentration in plasma at 1 hour after administration, the half-life of 2.5 hours, can give a hyperglycemic effect with an onset of 4 hours, reaches a peak at the 8 th hour of administration, and working duration of 12-24 hours ${ }^{20}$. Dexamethasone has a longer working time of 36-72 hours so that the effects of hyperglycemia can extend to the time of the next glucose level examination. This causes dexamethasone to dominate more on increasing $\mathrm{FBG}^{21-22}$.

The effect of chemotherapy on FBG and PPBG levels in this study was statistically significant ( $\mathrm{p}=$ 0.032 and $\mathrm{p}=0.002$ ) with a significance level of $5 \%$. This is in line with research by Gonzales et al (2013), an increase in FBG in $50 \%$ of subjects and PPBG in $20 \%$ of subjects. The average increase in FBG was $7.08 \pm 3.04$ $\mathrm{mmol} / \mathrm{L}$ and PPBG was $11.33 \pm 0.3 \mathrm{mmol} / \mathrm{L}^{8}$. In our study, the average increase in FBG was $177.5 \pm 28.99$ $\mathrm{mg} / \mathrm{dL}$ and PPBG $239.5 \pm 58.69 \mathrm{mg} / \mathrm{dL}$. 
In this study, we found 2 subjects $(9.53 \%)$ had new DM after getting chemotherapy. The two subjects did not experience acute complications of DM and were referred to Diabetes Mellitus Polyclinic of Dr. SoetomoTeaching Hospital Surabaya. Both of these subjects had comorbid factors such as for overweight, dyslipidemia, hypertension, and pre-diabetes. Subjects who had risk factors for pre-diabetes, had hyperglycemia up to $414 \mathrm{mg} / \mathrm{dL}$, febrile neutropenia, and were given insulin therapy. Whereas subjects who did not have prediabetes risk factors received anti-diabetes drug therapy orally. Both subjects experienced a peak increase in glucose levels at the fourth and fifth pre-lunch in accordance with previous studies that mentioned an increase in the dominant glucose level at pre-lunch and depending on the dose accumulation of agents that cause hyperglycemia ${ }^{7,9}$.

Some chemotherapy agents affect insulin resistance and $\beta$ cells. This is exacerbated by the presence of comorbidities in patients such as obesity, hypertension, and metabolic syndrome. Risk factors in this study included overweight - obesity ( 8 subjects), dyslipidemia (15 subjects), hypertension (5 subjects), and smokers (3 subjects). The accumulation of the duration and dose of the chemotherapy agent also influences the incidence of $\mathrm{DM}^{7}$. In addition, according to Lamar et al (2018), hyperglycemia can be induced by drugs through the mechanism of pancreatic $\beta$ cell destruction which causes a decrease in insulin secretion and sensitivity to insulin ${ }^{9}$.

Cyclophosphamide and epirubicin can cause immunologically destructive $\beta$ cells through induction of secretion of alpha interferon and lymphocytes cytokines $^{23}$. Doxorubicin causes worsening of insulin signaling, muscle atrophy induces pro-inflammation and induces anaerobic glycolytic metabolism in skeletal muscle ${ }^{24}$. Corticosteroids induce hyperglycemia through decreased glucose transporter type 4 (GLUT-4) regulation in cell membranes, increased gluconeogenesis, insulin resistance in muscle cells and adipose tissue, $\beta$ cell dysfunction, increased proteolysis and lipolysis, and inhibition of the enzyme 11- $\beta$ hydroxysteroid dehydrogenase type $1^{12,15,25-26}$.

Hyperglycemia contributes to the phenotype of cancer cell malignancy such as increased proliferation ability, apoptosis inhibition, metastasis, perineural invasion, resistance to chemotherapy through reducing the sensitivity of cancer cells to chemotherapy agents, and intolerance to chemotherapy ${ }^{27-28}$. The condition of hyperglycemia in malignant patients can affect the outcome of malignant therapy, complications related to malignancy and treatment of malignancy, length of stay, recurrence, and mortality ${ }^{29-30}$. Regulation of blood glucose levels isimportant in malignant patients ${ }^{13-14,17}$. It's related to the success of chemotherapy given, reducing the complications that may occur, reducing hospitalization days, reducing mortality, increasing the success rate of therapy, and life expectancy of cancer patients $^{7,8,9}$.

\section{Conclusion}

The peak of blood glucose during the first CHOP chemotherapy was in pre-dinner in the first day of chemotherapy. There was an increase in FBG and PPBG of NHL non-DM patients before and the sixth day the first CHOP chemotherapy. Incidence of new DM in the first CHOP chemotherapy was $9.53 \%$.

Conflict of Interest: No conflict of interest regarding the publication.

Source of Funding: This research was fund by author.

Ethical Clearance: Taken from Ethical Committee in Dr. Soetomo Teaching Hospital, Surabaya, Indonesia (1624/KEPK/XI/2019).

\section{References}

1. Indonesian Ministry of Health. Lymphoma Disease Data and Conditions in Indonesia. Jakarta: Indonesian Ministry of Health; 2015. 1-8.

2. Pufall. Glucocorticoids and Cancer. Adv Exp Med Biol. 2015; 872: 315-333.

3. American Cancer Society. Key Statistics for NonHodgkin Lymphoma. [Internet].2019. Available from: https://www.cancer.org/cancer/non-hodgkinlymphoma/about/key-statistics.html

4. Indonesian Ministry of Health. Guidelines for Management of Non-Hodgkin's Lymphoma. Jakarta: Indonesian Ministry of Health; 2015. 1-38.

5. National Comprehensive Cancer Network. B-Cell Lymphomas. [Internet]. 2019. Available from: https://www.NCCN.org

6. National Cancer Institute. Common Terminology Criteria for Adverse Events (CTCAE) Version 5.0. [Internet]. 2017. Available from: https://www. meddra.org/ 
7. Lee AY, Kurita N, Yokoyama Y, Seki M, Hasegawa Y, Okoshi Y, Chiba S. Glucocorticoid-Induced Diabetes Mellitus in Patients with Lymphoma Treated with CHOP Chemotherapy. Support Care Cancer. 2013; 22: 1385-1390.

8. Gonzalez JGG, Zavala LGM, Gutierrez RR, Almaguer DG, Gonzalez FJL, Perez HET, Saldivar GG, Perez JZV. Hyperglycemia Related to HighDose Glucocorticoid Use in Non-critically Ill Patients. Diabetology \& Metabolic Syndrome. 2013; 5(18): 1-7.

9. Lamar ZS, Dothard A, Kennedy L, Isom S, Robinson M, Vaidya R, Hurd D, McClain D, Lesser G. Hyperglycemia During First-Line R-CHOP or Dose Adjusted R-EPOCH Chemotherapy for NonHodgkin Lymphoma is Prevalent and Associated with Chemotherapy Alteration - A Retrospective Study. Leuk Lymphoma. 2018; 59(8): 1871-1877.

10. Indonesian Endocrinology Association. Guidelines for the Management of Dyslipidemia in Indonesia. Jakarta: IEA; 2019. 1-74.

11. Internasional Diabetes Federation. IDF Diabetes Atlas. $8^{\text {th }}$ Edition. 2017.

12. Harris D, Barts A, Connors J, Dahl M, Elliott T, Kong J, Keane T, Thompson D, Stafford S, Ur E, Sirrs S. Glucocorticoid-Induced Hyperglycemia is Prevalent and Unpredictable for Patients Undergoing Cancer Therapy: An Observational Cohort Study. Current Oncology. 2013; 20(6): e532-538.

13. Brady VJ, Grimes A, Amstrong T, Wood GL. Management of Steroid-Induced Hyperglycemia in Hospitalized Patients with Cancer: A Review. Oncology Nursing Forum. 2014; 41(6): E355-E365.

14. Rowbottom L, Stinson J, McDonald R, Emmenegger U, Cheng S, Lowe J, Giotis A, Cheon P, Chow R, Pasetka M, Thavarajah N, Pulenzas N, Chow E, DeAngelis C. Retrospective Review of the Incidence of Monitoring Blood Glucose Levels in Patients Receiving Corticosteroid with Systemic Anti-Cancer Therapy. Ann Palliat Med. 2015;4(2):70-77.

15. Jeong Y, Han HS, Lee HD, Yang J, Jeong J, Choi MK, Kwon J, Jeon HJ, Oh TK, Lee KH, \& Kim SK. A Pilot Study Evaluating Steroid-Induced Diabetes after Antiemetic Dexamethasone Therapy in Chemotherapy-Treated Cancer Patients. Cancer Res Treat 2016; 48(8): 1429-1437.
16. Farooki A, Flory J. Diabetes Management in Cancer Patients. [Internet]. 2016. Available from: https:// www.cancernetwork.com/oncology-journal/ diabetes-management-cancer-patients

17. Yang J, Jia B, Qiao Y, Chen W, Qi X. Variations of Blood Glucose in Cancer Patients during Chemotherapy. Nigerian Journal of Clinical Pratice. 2016; 19(6): 704-708.

18. American Diabetes Association. Standarts of Medical Care in Diabetes. Volume 42. 2019.

19. Ashariati A. Chemotherapy. In: Textbook of Internal Medicine. $2^{\text {nd }}$ Edition. Surabaya: Airlangga University Press; 2015. 433-436.

20. Katzung BG, Hall MK, Trevor AJ. Pharmacology Examination \& Board Review. Mc Graw Hill, Lange. 2019.

21. Gupta, Bhatia. Corticosteroid Physiology and Principles of Therapy. Indian Journal of Pediatrics. 2008; 75: 1039-1044.

22. Niema L. Pharmacologic Use of Glucocorticoids. [Internet]. 2019. Available from: https://www. UptoDate.com

23. Sharma PK, Misra AK, Singh V, Gupta A, Saroha S, Singh S. Cyclophosphamide and Epirubicininduced Diabetes Mellitus in Breast Cancer: A Rare Occurrence. Journal of Pharmacology and Pharmacotherapeutics. 2016; 7(3): 146-148.

24. Supriya R, Tam BT, Pei XM, Lai CW, Chan LW, Yung BY, Siu PM. Doxorubicin Induces Inflamatory Modulation and Metabolic Dysregulation in Diabetic Skeletal Muscle. Frontiers in Physiology. 2016; 7(323): 1-13.

25. Raalte DHV, Diamant M. Steroid diabetes: from mechanism to treatment?. The Journal of Medicine. 2014; 72(2): 62-72.

26. Suh S, Park MK. Glucocorticoid-Induced Diabetes Mellitus: An Important but Overlooked Problem. Endocrinology and Metabolism. 2017;32:180-189.

27. Duan W, Shen X, Lei J, Xu Q, Yu Y, Li R, Wu E, Ma Q. Hyperglycemia, a Neglected Factor during Cancer Progression. BioMed Research International. 2014: 1-10.

28. Mitri J, Castillo J, Pittas A. Non-Hodgkin Lymphoma in Patients with Diabetes Mellitus: A Meta-Analysis. Diabetes Care. 2008; 31(12): 23912397. 
29. Srokowski TP, Fang S, Hortobagyi GN, Giordano $\mathrm{SH}$. Impact of Diabetes Mellitus on Complications and Outcomes of Adjuvant Chemotherapy in Older Patients with Breast Cancer. Journal of Clinical Oncology. 2009; 27(13): 2170-2176.
30. Schultz H, Bjergaard UP, Jensen AK, Engelholm SA, Kristensen PL. The Influence on Survival of Glucocorticoid Induced Diabetes in Cancer Patients with Metastatic Spinal Cord Compression. Clinical and Translational Oncology. 2018; 11: 19-25. 